\title{
A Systematic Review of Systematic Reviews on the COVID-19 Pandemic
}

\author{
Zinat Nadia Hatmi ${ }^{1,2}$ (B)
}

Accepted: 10 January 2021 / Published online: 26 January 2021

(C) The Author(s), under exclusive licence to Springer Nature Switzerland AG part of Springer Nature 2021

\begin{abstract}
COVID-19 a systemic inflammation involving multiple organs, affecting all age groups, with high mortality rate, severe adverse outcomes, and high economic burden need to be described. A systematic review of systematic reviews conducted. We searched PubMed, OVID Medline, Cochrane library, COVID-19 resource centers of N Engl. J Med, AHA, and LITCOVID. Certainty of evidences was evaluated by GRADE approach. Meta-analysis according to random effects model was conducted. Seventy-one eligible systematic reviews are included in the study. A total of $86.5 \%$ of them had high quality, and $13.5 \%$ had medium quality. Meta-analysis results are presented in tabular format, and the remaining results are presented in narration fashion. COVID-19 involves blood vessels, lung, heart, nervous system, liver, gastrointestinal system, kidney, eyes, and other organs and infects adult and children, neonates, pregnant women, and elderly, transmitted via air born and droplet. Comorbidities associated with COVID-19 are HTN 20.7\%, CVD 9.6\%, DM 9.55\%, respiratory diseases 7\%, and 9\% of cigarette smoking. Prognostic factors for mortality among COVID-19 cases are acute cardiac injury, diagnosed CVD, DM, respiratory disease, and HTN. Prognostic factors for disease severity are CVD and HTN. Prognostic factors for disease progression were fever, shortness of breath, and smoking. There is no specific antiviral treatment. Preventive measures including physical distancing of $2 \mathrm{~m}$ and more, using PPE, avoiding social gatherings, quarantine, and isolation have been recommended. Encouraging telemedicine, online training, and homeschooling are highly recommended. Vaccine is approaching, and concerns exist about vaccine with a high efficacy. Modification of CVD and cardiometabolic risk became the cornerstone for sustainable control of pandemic.
\end{abstract}

Keywords Systematic reviews $\cdot$ COVID-19 $\cdot$ SARS-COV-2 $\cdot$ Natural history $\cdot$ Prevention $\cdot$ Treatment $\cdot$ Pandemic

\section{Introduction}

Global coronavirus disease 2019 (COVID-19) pandemic, which originated in Wuhan, China, has now about $41,189,939$ confirmed cases as officially reported by the governments of 215 countries and territories around the world on October 21, 2020 with 1,131,527deaths and case fatality rate of $2.74 \%$ which continues to change as the pandemic progresses [WORLDOMETER].

This article is part of the Topical Collection on COVID-19

Zinat Nadia Hatmi

hatmizn@sina.tums.ac.ir

1 Department of preventive medicine, Medical school, Tehran University of Medical Sciences, Purcina Ave, Medical Faculty, Building No 4, Second floor, Tehran, Iran

2 Department of Epidemiology, Centre for Public Health, Medical University of Vienna, Kinderspitalgasse 15, 1090 Vienna, Austria
The global burden of COVID-19 disease could be accurately estimated based on a combination of population-based cohort studies in society, household, school base, and workplace rather than laboratory-based or hospital-based surveys, alone.

The COVID-19 pandemic can be precisely described as a communicable disease pandemic superimposed on the existence of non-communicable disease pandemic of CVD, DM, and obesity.

The clinical manifestation spectrum of infection with Severe Acute Respiratory Syndrome Coronavirus-2 (SARSCOV- 2) ranges from mild self-limited disease to lifethreatening multiple organ involvement. It has initially been described as respiratory symptoms, pneumonia, and, in some cases, acute respiratory distress syndrome (ARDS) and shock [1]. Now, COVID-19 has presented as a systemic inflammation with multiple organ involvement including blood vessels, lung, heart, central nervous system, and other organs [2,3].

Recent reports describing complement-mediated thrombotic microangiopathy-like syndrome in COVID-19 cases have complicated the pathophysiological feature of the disease. 
We aimed to conduct a systematic review of published systematic reviews to provide comprehensive updated information on COVID-19.

\section{Methods}

Study design: we conducted a systematic review on COVID-19.

Types of included studies: systematic reviews on COVID-19.

Study population: confirmed cases of COVID-19.

\section{Search Strategy}

We searched PubMed, OVID Medline, Cochrane library, and COVID-19 resource centers of N Engl J Med and AHA, and LITCOVID up to June 10, 2020. Search was limited by published full-text article in English language. We searched for systematic reviews on COVID-19.

\section{Data Extraction and Management}

We screened titles and abstracts, retrieved published full-text articles, and extracted data based on PICOT algorithm. Accordingly, we extracted data on population/patients, interventions/ indicators, comparators, outcomes, and time frame/type of study of included articles.

Risk of bias assessment included studies: Two independent reviewers critically appraised articles using standard method of appraising systematic reviews. Adherent to GRADE approach, we screened the valid evidences among retrieved articles of different databases [4]. Agreement ratio on critical appraisal topic in articles was 94\% $(p<0.005)$, and disagreements were resolved by consensus. Systematic reviews on clinical trials have been critically appraised based on method evaluation in Cochrane Handbook for Systematic Reviews of Interventions and GRADE guideline.

Types of interventions: COVID-19 management including pharmaceutical and non-pharmaceutical interventions.

Types of outcomes: outcome of interest was efficacy of interventions and natural history of the COVID-19.

\section{Data Synthesis}

We extracted the certainty of evidences according to GRADE approach. GRADE approach was also used to present summary of evidence findings [4-13].

Homogenous results were managed by conducting metaanalysis.
Narrative synthesis was the best choice for summarizing systematic inference on various results of the included studies. We have also described data on tabular format.

\section{Data Analysis}

Meta-analysis method: Random-effects model was used. Pooled risk ratios, prevalence, and frequencies were estimated associated with $95 \%$ confidence intervals. Mantel-Haenszel test was used to estimate parameters. Statistical analysis has been planned and conducted using statistical package of IBM SPSS Statistics for Windows, Version 22.0. Armonk, NY: IBM Corp. Statistical relationships were considered significant at $P<0.05$.

Funding resource: No funds, grants, or support was received.

\section{Results}

PRISMA flow diagram reported various studies assessed for further evaluation and including in the review (Fig. 1).

One hundred forty-eight full-text articles were assessed for inclusion based on the GRADE approach. Seventy-one systematic reviews were eligible to include in the systematic review. Critical appraisal assessed the quality of the included 71 systematic reviews; accordingly, $86.5 \%$ of studies evaluated as high/good quality, and the remaining $13.5 \%$ evaluated as medium quality.

Table 1 presents the included studies in the systematic review and meta-analysis based on PICOI items.

Mean age of COVID-19 cases in different studies was $58.05 \pm 7.24$. Gender distribution of COVID-19 cases demonstrated that $55.85 \%(45.24-64.39)$ were male.

\section{Clinical Manifestations}

Most frequent general symptoms are fever, cough, and fatigue [14] which is presented in Table 2. Dyspnea, anorexia, productive sputum, myalgia [15], sour throat, nausea, dizziness, diarrhea, headache, vomiting, and abdominal pain are other symptoms (with frequency of 82.2 to $2.2 \%$ in decreasing order) [16].

Organ-specific symptoms are pharyngodynia and nasal congestion with rare rhinorrhea [14]. Face pain and nasal obstruction were the most specific otolaryngological symptoms, and olfactory and gustatory dysfunctions [15]. In a multinational European study, the prevalence of ageusia or dysgeusia was reported 49.8\% [17]. The results of multivariate analysis presented in Table 3. 


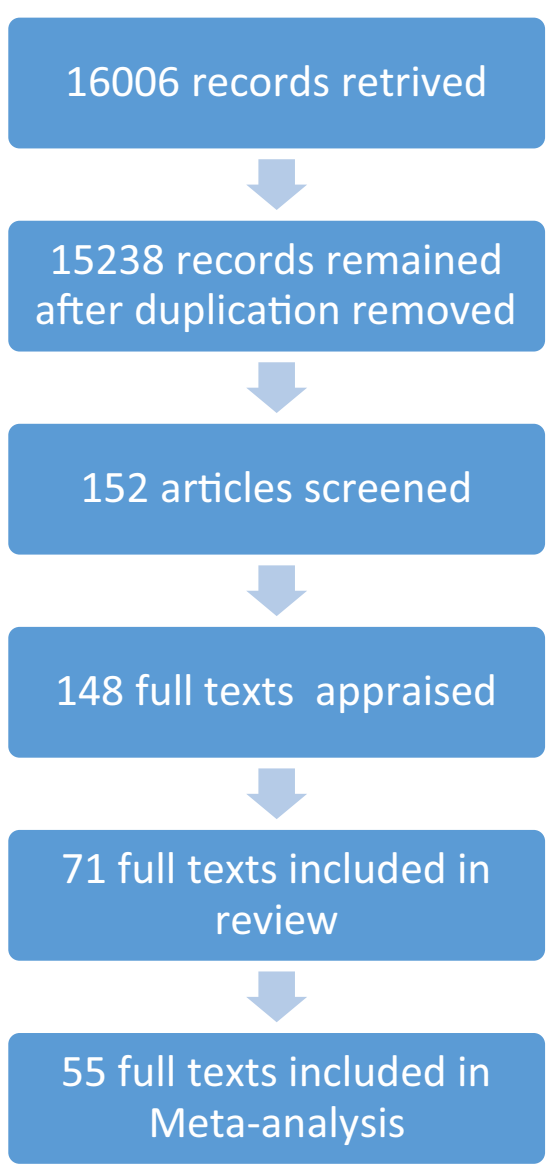

Fig. 1 PRISMA flow diagram of the systematic review

Cardiovascular presentations of SARS-COV- 2 have been described as myocarditis [2], myocardial injury, arrhythmia, venous thrombosis [18], cardiogenic shock, and heart failure [1]. Cardiac injury is significantly associated with poor prognosis of COVID-19 patients and higher mortality rate [1, 19]. Circulatory biomarkers of myocardial injury increased in nonsurvivors of COVID-19 [20]. Another systematic review of 17 studies involving 5815 COVID-19 patients reported the most prevalent cardiovascular complication of COVID-19 as heart failure, cardiac injury, and arrhythmia [21].

Table 4 demonstrates the pooled prevalence of comorbidities associated with COVID-19.

Meta-analysis revealed pooled estimation of different COVID-19 outcomes and complications, which is presented in Table 5.

Coincidence of cardiovascular disease (CVD) and COVID-19 is associated with of 4.85 (95\%CI 3.07-7.70) times in hospital mortality increase. Also, the presence of hypertension associated with COVID-19 will tend to inhospital mortality of about 3.67 (95\% CI 2.31-5.83) times [22].
Gastrointestinal symptoms of COVID-19 are vomiting, diarrhea, and abdominal pain or discomfort along with shedding viral RNA (in $48 \%$ of cases) in stool which could persist about 33 days after disease onset [23].

A systematic review of 35 studies involving 6686 COVID-19 patients demonstrated that prevalence of having three symptoms of nausea or vomiting, diarrhea, and loss of appetite was $15 \%$. Abnormal liver tests were reported in 19\% of COVID-19 cases. Gastrointestinal involvement compromised COVID-19 cases to disease complications [24].

A systematic review of 17 studies involving 2477 COVID19 patients revealed that severe COVID-19 cases have reported abdominal pain seven times (OR $=7.17$ 95\% CI 1.95 26.34) more than that of non-severe cases [25].

Clinical manifestation of COVID-19 in children [26] is described as fever, cough, and gastrointestinal symptoms. Lymphopenia has been reported in $32 \%$ of cases and severe lymphopenia in $9 \%$ of infected children.

COVID-19 presentation during pregnancy [27] in confirmed cases of pneumonia was fever, cough, and dyspnea. Pregnancy outcome among infected patients reported miscarriage rate of $39.1 \%$, preterm birth $24.3 \%$, premature rupture of membrane $20.7 \%$, pre-eclampsia $16.2 \%$, and fetal growth retardation $11.7 \%$.

Perinatal exposure to SARS-COV-2 in 222 newborns evaluated in 20 different studies resulted in 5.8\% infection rate with a wide spectrum of clinical presentations [28]. Current knowledge regarding natural history of COVID-19 cannot confirm vertical transmission of SARS-COV-2 [28].

Eighty-four percent of deliveries were cesarean section. Perinatal death rate was $11.1 \%$, and $57.2 \%$ of newborn babies were needed to be admitted in the neonatal intensive care unit [27]. Another study [29] reported $96 \%$ cesarean delivery rate, preterm birth of $39 \%$, and median gestational age of 36.5 weeks. Another systematic review of nine studies did not demonstrate maternal mortality ration in pregnant COVID-19 patients. However, adverse events related to pregnancy such as $\mathrm{C}$-section delivery, preterm labor, low birth weight, and NICU admission rate were reported at high a level [30].

A systematic review of 44 studies reported that children have accounted to $1-5 \%$ of symptomatic COVID-19 cases. So far, the disease in children was reported milder with better prognosis than adult COVID-19 cases [31].

Another systematic review of 24 studies suggested a similar attack rate of infection among children to adult patients; however, asymptomatic pattern or mild disease presentation tended to lower medical attention to COVID-19 in children [32]. 


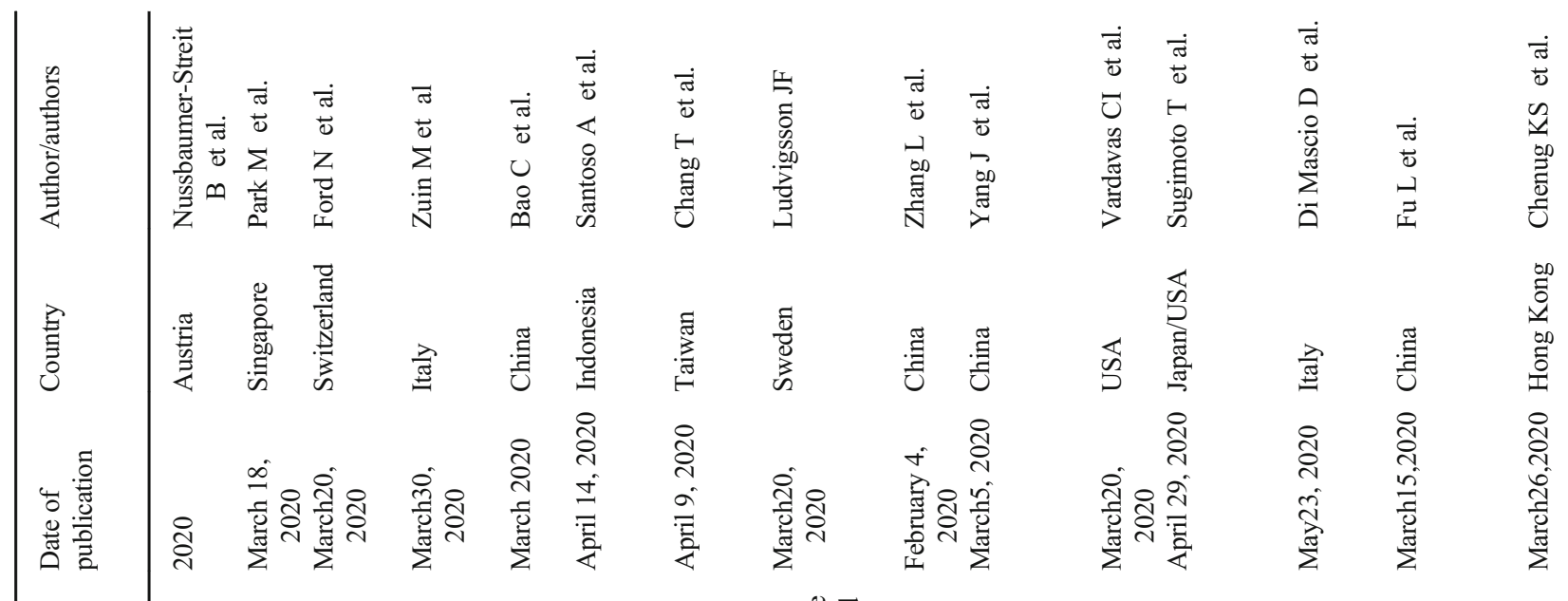

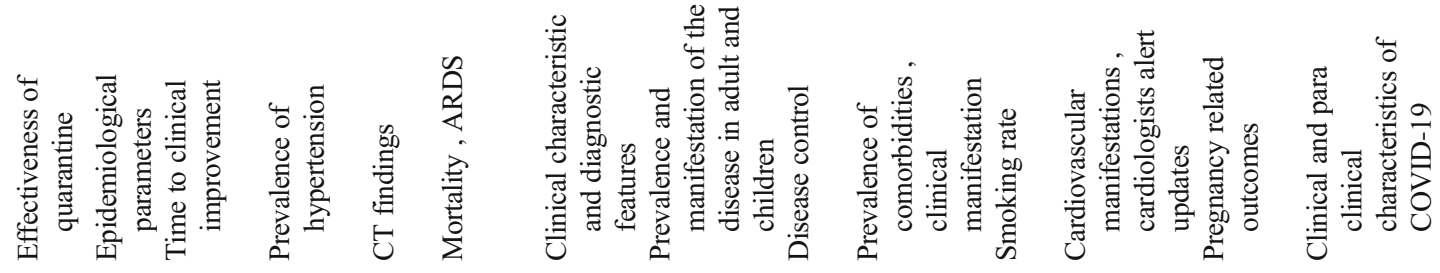

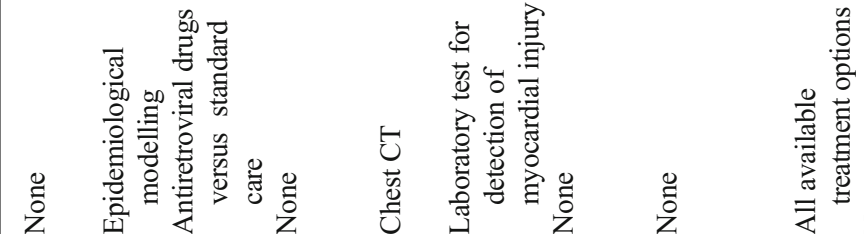

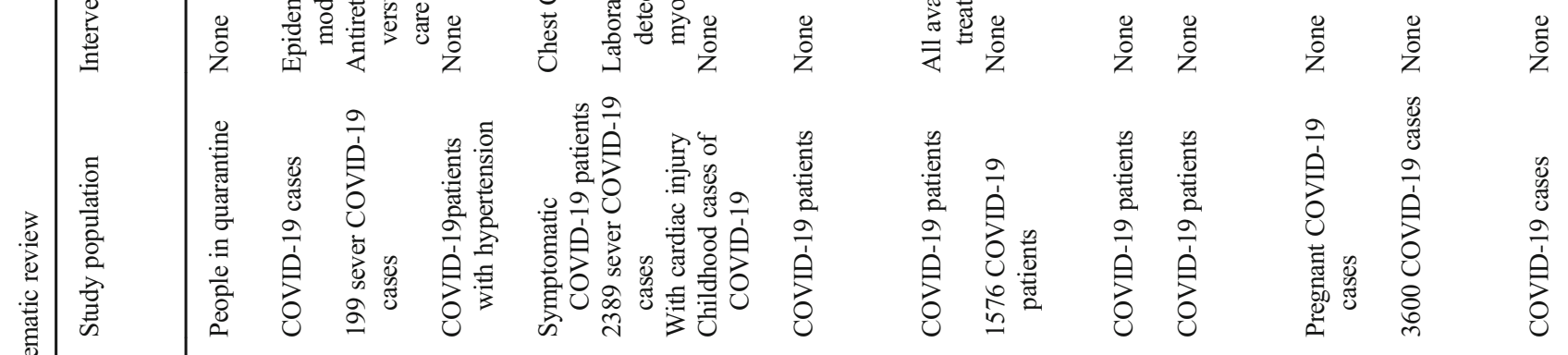

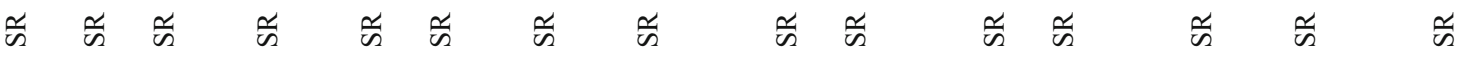

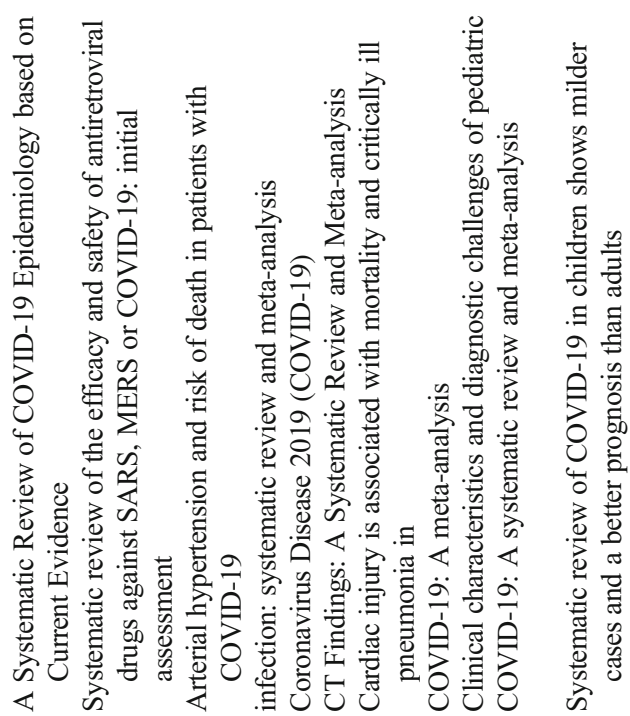

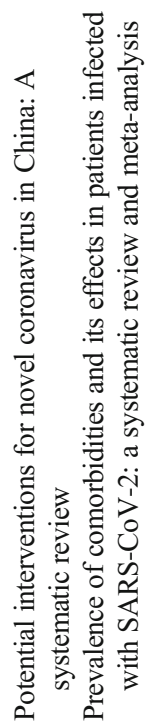

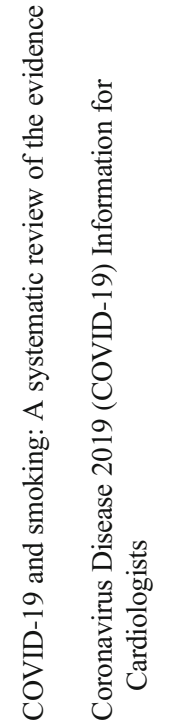

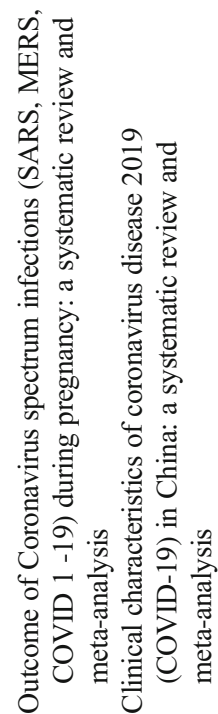




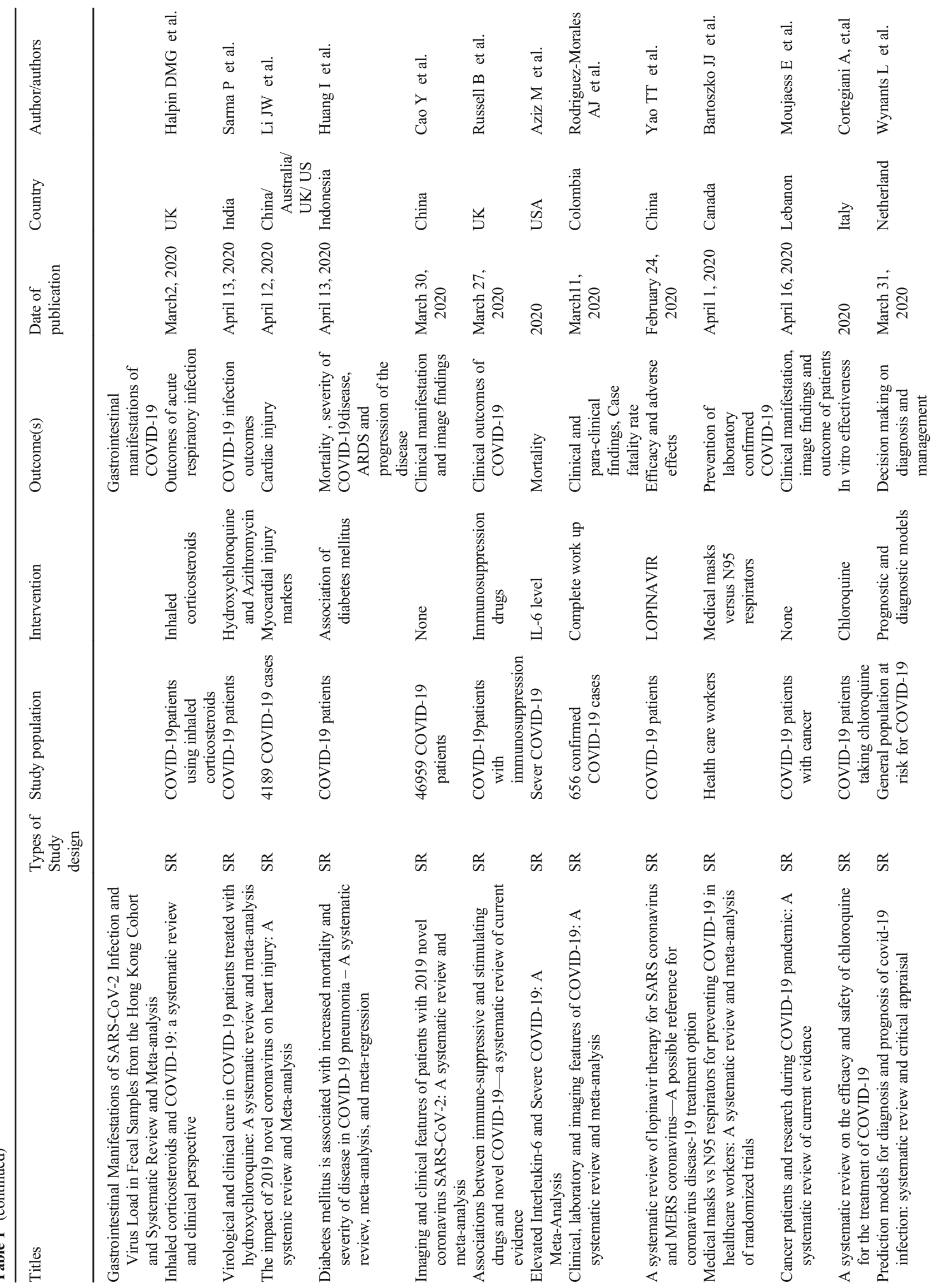




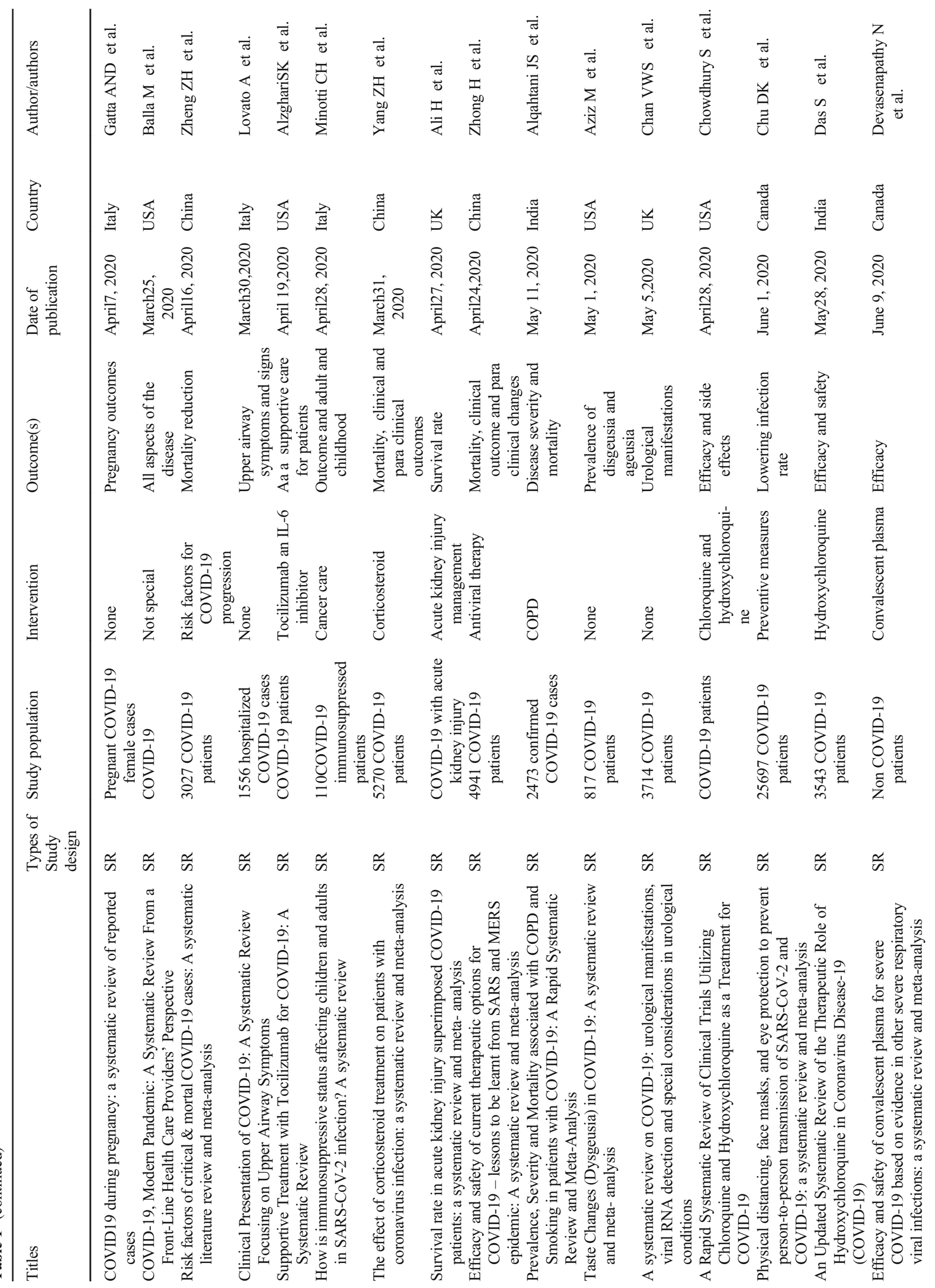




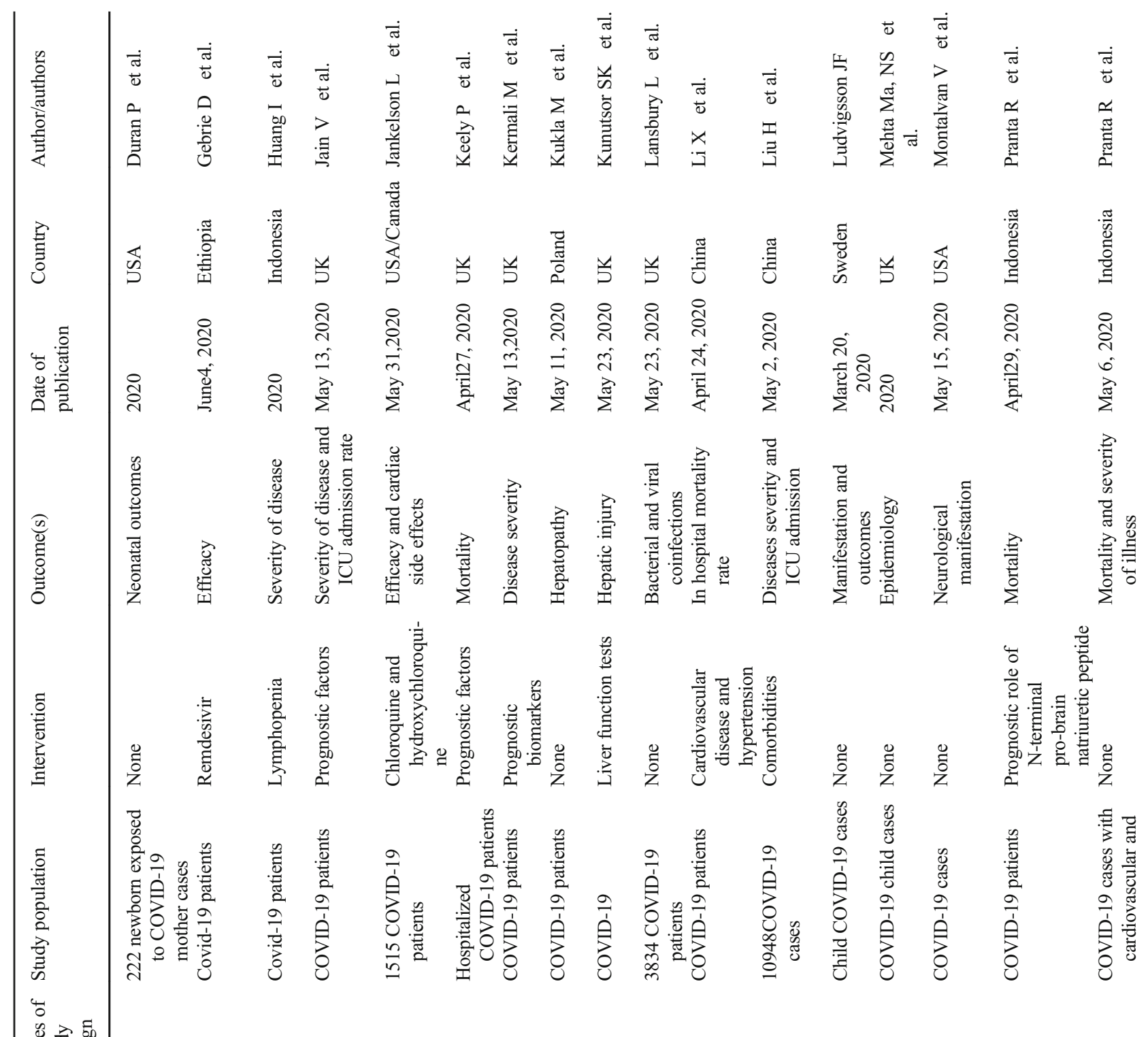

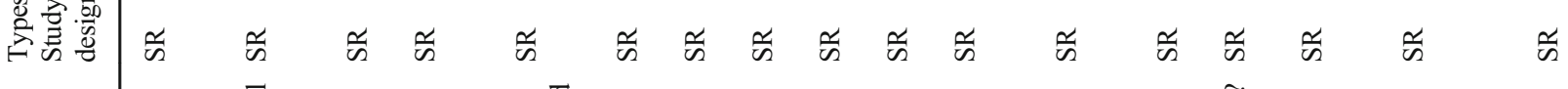

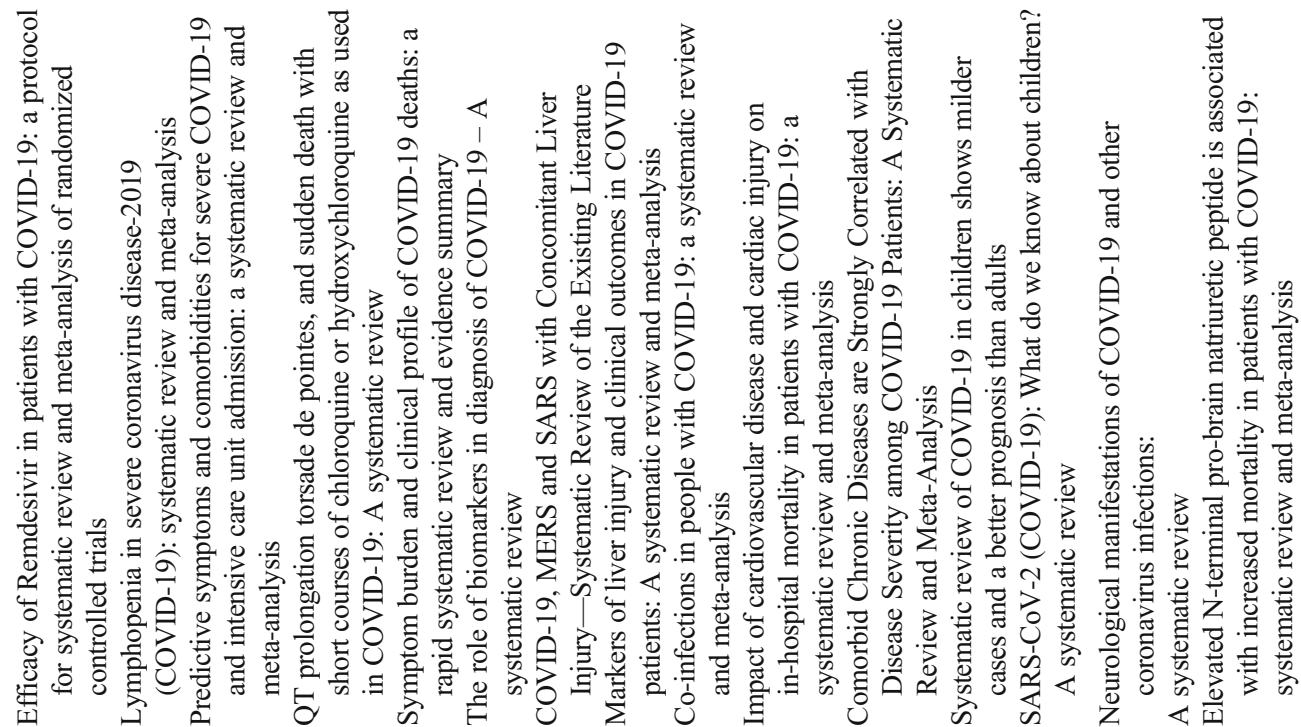




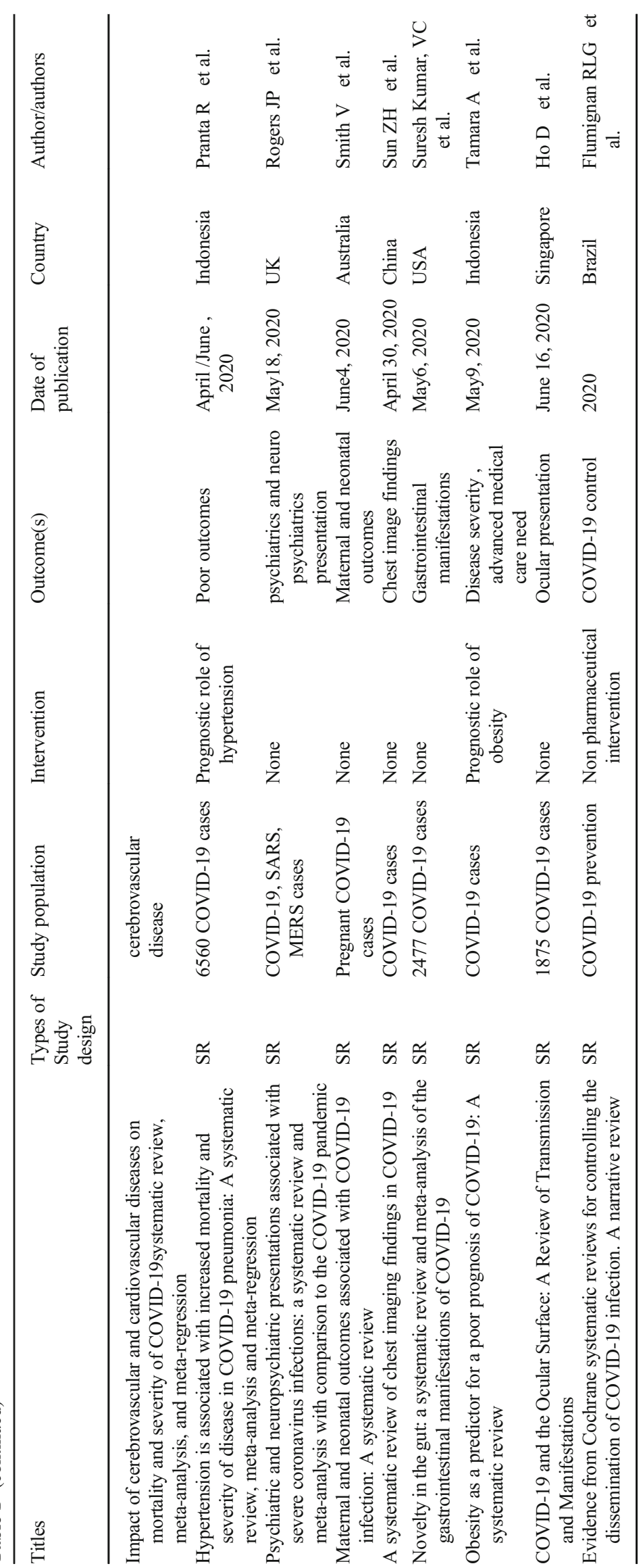


Table 2 Pooled prevalence of general clinical manifestations of COVID-19

\begin{tabular}{lll}
\hline $\begin{array}{l}\text { General manifestations } \\
\text { of COVID-19 }\end{array}$ & $\begin{array}{l}\text { Pooled } \\
\text { prevalence }\end{array}$ & $\begin{array}{l}\text { 95\% confidence } \\
\text { interval }\end{array}$ \\
\hline Fever & 82.68 & $73.30-88.35$ \\
Cough & 57.67 & $47.22-66.27$ \\
Fatigue & 37.98 & $28.18-46.78$ \\
Dyspnea & 35.32 & $26.36-44.75$ \\
Gastrointestinal system & 14.80 & $8.53-22.14$ \\
Headache & 6.00 & $2.73-12.48$ \\
\hline
\end{tabular}

In a systematic review including 3714 COVID-19 patients, urological symptoms were not reported. However, urinary viral RNA shedding was reported among 5.74\% of COVID19 patients [33]. Also, acute kidney injuries in COVID-19 patients were associated with a mortality rate of $93.27 \%$ [33].

Age range of most cases is 30-79 years. Common comorbidities seen with COVID-19 infection consisted of hypertension $(30.7 \%)$, diabetes mellitus (14.3\%), cardiovascular diseases $(11.9 \%)$, cerebrovascular disease $(6.6 \%)$, malignancy $(4.3 \%)$, chronic liver, lung and kidney disease $(2.8 \%, 2.4 \%$, $2.1 \%$ respectively), HIV (1.4\%), and immunodeficiency $(0.2 \%)[16]$

Hypertension, cardiovascular disease (CVD), and chronic respiratory condition are accompanied with a severe form of COVID-19 infection [34].

A systematic review of 24 studies involving 10,948 COVID-19 patients reported that coincidence of diabetes mellitus (DM), CVD, coronary artery disease (CAD), and

Table 3 Pooled prevalence of specific clinical manifestation of COVID-19

\begin{tabular}{lcc}
\hline Clinical manifestations & Pooled prevalence & $95 \%$ confidence interval \\
\hline Shortness of breath & 32.6 & $23.67-41.66$ \\
Diarrhea & 7.8 & $3.43-13.75$ \\
Ageusia or dysgeusia & 49.8 & $39.42-58.65$ \\
Polypnea & 47 & $37.51-56.71$ \\
Muscle soreness & 35.5 & $27.27-4576$ \\
Chest distress & 31.2 & $22.78-40.63$ \\
Nasal congestion & 3.7 & $1.57-9.84$ \\
Pharyngodynia & 12.4 & $7.00-19.61$ \\
Acute kidney injury & 7.5 & $4.11-15$ \\
Nausea /vomiting & 5.5 & $2.75-12.46$ \\
Shock & 6.2 & $3.57-11.82$ \\
ARDS & 30.80 & $21.89-39.58$ \\
\hline
\end{tabular}

$A R D S$ acute respiratory distress syndrome hypertension with COVID-19 was more common than chronic respiratory disease [35].

SARS-COV-2 receptors have been shown to present in nervous system. Consequently, the neurological manifestation of SARS-COV-2 virus infection is reported as non-focal signs of agitation, corticospinal tract sign, dys executive syndrome, and confusion [36, 37]. A systematic review of 67 different studies reported the most common symptoms as hyposmia, headache, weakness, and change in consciousness [38]. Furthermore, delirium (confusion) and agitation has been reported among patients admitted to ICU in a systematic review of 65 studies recruiting 3559 COVID-19 patients [39].

Summation of 43 studies revealed that hepatic involvement in COVID-19 could be explained as mild to moderate elevation of transaminases, hypoalbuminemia, and prolongation of prothrombin time [40].

A systematic review involving 1875 confirmed cases of COVID-19 reported that $4.3 \%$ of cases have shown ocular presentation, and $2.9 \%$ have viral nucleic acid in ocular swab. Conjunctivitis was reported as the main clinical manifestation of COVID-19 [41].

\section{Smoking Status and COVID-19 Infection}

It has been reported that among the severe cases of CODIV$19,16 \%$ were current smokers versus $11.8 \%$ smoking rate among non-severe one [42]. Current smoking is associated with more severe complications and higher mortality rate [43].

\section{Infectious Agent}

SARS-COV-2-virus is a single, positive-stranded RNA virus. Coronavirus family structural proteins have been described as spike protein $(\mathrm{S})$, membrane protein $(\mathrm{M})$, envelope $(\mathrm{E})$, and nucleocapsid (N) [44].

Viral RNA is enveloped in a bilayer lipid crowned with two spike proteins (S-protein) [16]. The viral S1-protein binds with ACE2 protein receptors of human host cells, and then fuses host cells with S2 protein. Fusion with host cell

Table 4 Pooled prevalence of comorbidities associated with COVID19 or risk factors

\begin{tabular}{llc}
\hline Comorbidities & Pooled prevalence & 95\% confidence interval \\
\hline Hypertension & 20.7 & $13.34-28.88$ \\
Cardiovascular diseases & 9.6 & $4.81-16.23$ \\
Diabetes mellitus & 9.55 & $5.52-17.44$ \\
Respiratory diseases & 7 & $3.84-12.57$ \\
Cigarette smoking & 9 & $6.13-21.43$ \\
\hline
\end{tabular}


Table 5 Various clinical outcomes and complications of COVID-19

\begin{tabular}{lcc}
\hline Various clinical outcomes of COVID-19 & $\begin{array}{c}\text { Pooled } \\
\text { percentage }\end{array}$ & $\begin{array}{l}\text { 95\% confidence } \\
\text { interval }\end{array}$ \\
\hline Complications & 36.2 & $26.36-44.75$ \\
Mortality rate & 15.5 & $9.31-23.28$ \\
Case fatality rate & 5.1 & $2.15-11.18$ \\
Mortality rate of cigarette smoker COVID-19 patients & 38.5 & $29.10-47.79$ \\
Mortality rate of COVID-19 patients with acute kidney injury & 93.27 & $86.25-95.57$ \\
Coinfections (bacterial) & 7 & $3.82-12.57$ \\
Coinfection rate in ICU admitted COVID-19 patients & 14 & $8.53-22.14$ \\
Viral coinfection & 3 & $1.03-8.45$ \\
Low birth weight & 42.8 & $33.73-52.78$ \\
Perinatal death & 7 & $1.71-7.05$ \\
Preterm birth & 52.45 & $42.32-61.54$ \\
NICU admission of neonates born with confirmed COVID-19 & 67.06 & $57.31-75.44$ \\
$\quad$ mothers & & \\
Cesarean section in COVID-19 pregnancies & 86.66 & $79.02-92.24$ \\
Miscarriage & 39.1 & $31.49-49.80$ \\
Preeclampsia & 6.2 & $3.78-11.84$ \\
Growth restriction & 11.7 & $7-19.81$ \\
Premature rupture of membrane & 20.7 & $14.17-29.98$ \\
ICU admission of COVID-19 cases & 18.96 & $12.51-27.78$ \\
Multiple organ dysfunction among COVID-19 cases & 14.25 & $8.53-22.14$ \\
Invasive ventilation need & 3.4 & $2.06-16.22$ \\
Severe COVID-19 cases among all COVID-19 cases & 25.6 & $19.27-36.43$ \\
\hline & &
\end{tabular}

$I C U$ intensive care unit membrane completes with lipid layers, and consequently, viral RNA releases into host cell cytoplasm [16].

$\mathrm{N}$ protein is responsible for viral pathogenesis, replication, and RNA packaging [44]. Ab against $\mathrm{N}$ protein has been detected among COVID-19-infected patients [44].

\section{Mode of Transmission}

The main route of transmission for rapidly spreading SARSCOV-2 is direct host-to-host contact.

Airborne transmission of viral small particles during a person-to-person contact over a distance of $2 \mathrm{~m}$ [45] could explain the rapid and massive spread of SARS-COV-2. Also, transmission of viral particles via droplet [16] and gas cloud emitted from sneeze and cough which can travel up to 6-8 $\mathrm{m}$ away [46] has been described.

Comprehensive understanding of SARS-COV-2 transmissibility is crucial for the prediction of the pandemic course and possibility of sustained transmission.

\section{Incubation Period}

Mean latency period lies between 3 and 9 days with a variation ranged from 0 to 24 days [16]. Serial interval mean is estimated 3-8 days, which can cause viral transmission by an infected person before symptom onset. This can describe $44 \%$ of transmissions during the pandemic course [16].

\section{Period of Communicability}

COVID-19, an emerging infectious disease, tends to be presented as asymptomatic in about $18 \%$. Asymptomatic ones are mainly younger persons. In elderly, most infections are symptomatic with different severity measures. Symptoms are about to resolve after 10 days in $90 \%$ of cases and resolve after 15 days to onset in all cases [16]. However, viral RNA shedding via nasopharynx (18 days) and feces (19 days) persists after symptoms resolved and even longer in severe cases, which has been estimated about 25 days after disease onset. Viral load in severe cases is estimated to be 60 times more than mild cases [16].

US CDC and European CDC guidelines clearly stated that replication competent virus has been detected in most COVID-19 cases (mild to moderate severity cases) up to 10-15 days after symptom onset. However, in severe cases of COVID-19, the infectivity period remains longer and is estimated to be 10-20 days after symptom onset. Recovered 
symptomatic persons continue to shed viral RNA in the upper respiratory system 3 months after disease onset.

\section{Diagnosis}

\section{Viral Tests}

The gold standard test for diagnosis of SARS-COV-2 is based on the detection of genetic materials of the virus. RT-PCR nucleic acid-based test tracks viral material from a respiratory tract swab specimen of the patients infected with SARS-COV2 with minimum false-positive rate. Nasopharyngeal swab specimen is recommended in most cases. Lower respiratory tract samples are reserved for special occasions.

Nowadays, cell culture is not recommended [44]. Viral genome sequencing is impractical for diagnostic purposes [44].

Serological tests which focused on host immunological response to the infection with SARS-COV-2 determine IgM and $\mathrm{IgG}$ antibodies $(\mathrm{Ab})$ to detect burden of COVID-19, asymptomatic cases, basic reproduction rate, and mortality rate (MR) [44].

Laboratory test findings: Blood sample tests revealed the following changes: decreased number of eosinophils $78.8 \%$, lymphopenia $68.7 \%$, elevated AST level $63.4 \%$, high level of C-reactive protein $60.7 \%$, elevated PT level $58.0 \%$, high level of LDH $47.2 \%$, elevated D-dimer level $46.4 \%$, thrombocytopenia $36.2 \%$, elevated ALT level $21.3 \%$, and high HStroponin level in $12.5 \%$ [16].

Immune system response translated to elevated CRP level, high IL-6 level and lymphopenia in mild to moderate severity cases, and increased level of IL-2, TNF- $\alpha$, and IL-10 in severe cases of COVID-19 have been reported.

\section{Imaging}

Chest X-ray findings: bilateral pneumonia was more common than unilateral pneumonia.

Chest CT scan abnormalities: bilateral ground glass opacity at early stage of the disease and consolidations at advanced stage of the infection [16]. Validity of chest CT scan findings compared with RT-PCR results revealed a sensitivity of 84 $94 \%$, specificity of $25-80.5 \%$, positive likelihood ratio of 1.17 , and negative likelihood ratio of 0.84 [16].

A systematic review of 45 studies composed of 4410 COVID-19 patients reported consistently that the most common chest CT finding of COVID-19 was bilateral peripheral/ subpleural ground glass opacity with or without consolidations [47].

Another systematic review of 55 studies confirmed the above common chest $\mathrm{CT}$ findings. Besides, this research reported $13.31 \%$ normal CT in COVID-19 patients with pneumonia [48].
Different paraclinical findings in meta-analysis have been presented in Table 6.

\section{Coinfections}

The most common bacterial and viral coinfections associated with COVID-19 are described as mycoplasma pneumonia (17.3\%), chlamydia (11.9\%), Legionella (8.82\%), Influenza A $(6.47 \%)$, Influenza B (5.76\%), and respiratory syncytial virus (RSV) (1.44\%) [16].

Another systematic review of 30 studies involving 3834 COVID-19 patients revealed that overall co-infection rate in hospitalized patients was 7\%. In a mixed setting of hospital ward and intensive care unit (ICU), the most common germs were Mycoplasma pneumoniae, Pseudomonas aeruginosa, and Haemophilus influenzae. Viral co-infection reported as $3 \%$ comprises of RSV and Influenza A [49].

\section{Treatment}

Different treatment modalities have been recommended for COVID-19 around the world. Remdesivir, a nucleotideanalogue antiviral agent used for Ebola, is supposed to stop infection with SARS-COV-2 in a randomized placebocontrolled trial conducted on 1059 COVID-19 patients; 538 patients were allocated to receive intravenous Remdesivir arm (200 mg loading dose on first day followed by $100 \mathrm{mg}$ daily for 9 days) versus placebo for 10 days. Remdesivir significantly shortened recovery time to 11 days versus 15 days of placebo, decreased mortality rate in 14 days to $7.1 \%$ compared with $11.9 \%$ of placebo administration, and lower adverse events of $21.1 \%$ versus $27 \%$ [50]. An ongoing systematic review of randomized controlled trials on efficacy of Remdesivir in COVID-19 patients will provide us with more features of the treatment effect of this drug [51].

A systematic review of 155 studies involving 9152 COVID-19 patients concluded that lopinavir/ritonavir use was associated with a significant shortening of hospital stay 11.7 days ( \pm 1.09 ) or symptom resolution [52].

Another systematic review [53] of 11 retrospective studies involving 4941 COVID-19 patients has shown the superiority of LOPINAVIR and Ritonavir compared with other antiviral agents.

Current evidence derived from systematic reviews did not support the use of chloroquine and hydroxychloroquine in COVID-19 [54, 55]. A systematic review of 14 studies involving 1515 COVID-19 patients treated with these agents reported $10 \%$ incidence of QT interval prolongation which increases the risk of cardiac arrhythmia [56].

Quality of existence evidence on efficacy of convalescent plasma in COVID-19 is very low and non-conclusive [57]. 
Table 6 Paraclinical findings (laboratory and chest CT) of COVID-19 cases

\begin{tabular}{|c|c|c|}
\hline Paraclinical findings in COVID-19 & Frequency $(\%)$ & $95 \%$ confidence interval \\
\hline Lymphopenia & 67.3 & $57.31-75.44$ \\
\hline Leukopenia & 32.55 & $22.76-40.18$ \\
\hline Thrombocytopenia & 13 & $7.76-20.98$ \\
\hline \multicolumn{3}{|l|}{ Chest CT findings in COVID-19: } \\
\hline Normal CT & 13.31 & $7.76-20.96$ \\
\hline Ground glass opacity & 64.87 & $55.25-73.64$ \\
\hline Ground glass opacity with consolidations & 55.7 & $46.23-65.33$ \\
\hline Consolidation & 44.8 & $35.6-54.76$ \\
\hline Severe chest CT findings & 88.5 & $81.3-93.75$ \\
\hline Change in chest $\mathrm{CT}$ & 83 & $74.45-89.11$ \\
\hline Bilateral findings & 78.92 & $70.02-85.83$ \\
\hline Peripheral & 71.15 & $61.64-78.90$ \\
\hline Central & 3.57 & $1.75-9.84$ \\
\hline Central associated with peripheral & 31.12 & $22.80-40.37$ \\
\hline Three or more lobe & 70.8 & $61.46-78.99$ \\
\hline Right lower lobe & 87.21 & $79.02-92.24$ \\
\hline Left lower lobe & 81.04 & $72.22-87.49$ \\
\hline Bilateral lower lobes & 65.22 & $55.25-73.64$ \\
\hline Right upper lobe & 63.22 & $52.25-71.38$ \\
\hline Right middle lobe & 54.95 & $45.24-64.39$ \\
\hline Left upper lobe & 69.43 & $60.42-78.11$ \\
\hline Bilateral upper lobe & 60.87 & $51.20-69.98$ \\
\hline \multicolumn{3}{|l|}{ Viral RNA findings: } \\
\hline Stool SARS-COV-2 RNA positive & 56.96 & $47.22-66.27$ \\
\hline Urine SARS-COV-2RNA positive & 5.74 & $2.78-12.48$ \\
\hline \multicolumn{3}{|l|}{ Laboratory findings: } \\
\hline \multicolumn{3}{|l|}{$(\operatorname{mean} \pm 95 \% \mathrm{CI})$} \\
\hline C-reactive protein $(\mathrm{mg} / \mathrm{L})$ & 52.26 & $48.1-56.40$ \\
\hline $\begin{array}{l}\text { Viral SARS-COV-2 load (mean } \log _{10} \text { viral load calculated } \\
\text { as copies per } \mathrm{mL} \text { ) }\end{array}$ & 5.1 & $2.15-11.16$ \\
\hline
\end{tabular}

CT computerized tomography, CI confidence interval

\section{Prognosis}

Prognostic factors extracted from systematic reviews estimated in meta-analysis have been presented in Table 7.

A systematic review (SR) of 24 studies involving 3099 COVID-19 patients revealed a poor prognosis for those admitted with lymphopenia. Lower lymphocyte count was associated with severe COVID-19, progression toward ARDS, and higher mortality rate [58]. Another systematic review on prognostic biomarkers reported that decreased level of lymphocytes and platelets was associated with progression to severe COVID-19 [59].

An SR comprising seven studies recruiting 1813 COVID19 patients has shown the prognostic value of dyspnea symptom for predicting severe COVID-19 and intensive care unit (ICU) admission [60].

Association of cerebrovascular diseases with COVID-19 will predict a higher mortality rate; an SR of 4448 patients evaluated in 16 studies also revealed that concomitant cardiovascular disease and COVID-19 resulted in both higher mortality rate and progression to severe COVID-19 [61].

An SR of six studies recruiting 967 patients reported higher levels of N-terminal pro-brain natriuretic peptide (NT pro BNP) in non-survivor of COVID-19 and predicted mortality with hazard ratio (HR) of 1.37 (95\% CI 1.19-1.57) [62].

Hypertension (HTN) is a strong predictor of poor prognosis among COVID-19 patients including higher rates of 
Table 7 Various prognostic factors for different COVID-19 outcomes

\begin{tabular}{lcl}
\hline Prognostic factors for different COVID-19 outcomes & Relative risk & 95\% confidence interval \\
\hline $\begin{array}{l}\text { Comorbidity of documented cardiovascular disease } \\
\quad \text { for mortality rate of COVID-19 }\end{array}$ & 4.06 & $3.25-4.86$ \\
Acute cardiac injury for mortality rate of COVID-19 & 10.89 & $5.71-16.04$ \\
Hypertension for severity of COVID-19 & 2.20 & $2.04-2.35$ \\
Cardiovascular disease for severity of COVID-19 & 2.83 & $2.26-3.39$ \\
Hypertension for mortality of COVID-19 & 2.86 & $2.44-3.27$ \\
Diabetes mellitus for mortality of COVID-19 & 3.68 & $2.99-4.40$ \\
Respiratory disease for mortality of COVID-19 & 3.51 & $1.94-5.07$ \\
Cigarette smoking for disease progression in COVID-19 & 2.19 & $1.88-2.49$ \\
Fever and shortness of breath for disease progression & 4.16 & $1.09-12.16$ \\
\hline
\end{tabular}

mortality, severe COVID-19, ARDS, need for ICU admission, and progressive illness [63].

Obesity is an independent prognostic factor for severity of the disease and fatal outcomes. COVID-19 patients with body mass index (BMI) greater than $35 \mathrm{~kg} / \mathrm{m}^{2}$ need more than seven times $(\mathrm{OR}=7.36$ 95\% CI 1.63-33.14) of use of mechanical ventilation compared with non-obese counterparts [64].

\section{Mode of Death}

Information regarding COVID-19 patient mode of death and end of life care should be improved.

The most common symptom described in dying patients is dyspnea [65].

A large cohort of 1145 confirmed COVID-19 cases with 67 days of follow up suggested the use of viral load as a risk assessment tool which can predict mortality with hazard ratio of 1.07 , 95\% CI (1.03-1.11). Mean $\log _{10}$ viral load was reported 5.6 copies per $\mathrm{mL}$, and the median $\log _{10}$ viral load was calculated 6.2 copies per $\mathrm{mL}$ [66]. A fully adjusted multivariable model revealed a significant association between viral load and mortality in COVID-19 cases.

\section{Prevention}

\section{Non-pharmaceutical Preventive Measures}

At the present time, with no effective available vaccine and specific treatment modalities, prevention of COVID-19 should be focused on protection at individual and community level and contact tracing. We can descend transmission rate by implementing personal protection equipment (PPE) in all settings.

More effective distancing defined as distance of $2 \mathrm{~m}$ causes a significant lower infection rate compared with less than $2 \mathrm{~m}$ distancing. Protection probability will increase as length of distance increased by relative risk $=2.02(\mathrm{RR})$ [67].

A systematic review of 172 studies and 25,697 cases demonstrated that effective social distancing of more than $1 \mathrm{~m}$ and wearing standard face mask and eye protection in public were reported to be associated with less SARS-COV-2 infection rate [67].

Optimum use of facemask in both public and health care setting has been associated with a significant reduction in infection rate. Superiority of N95 facemask compared with surgical and reusable 12-16 layers of cotton mask has been demonstrated [67].

Eye protection associated with using facemask and effective distancing has been shown to enhance protection against fatal SARS-COV-2 and resulted in significant decrease in infection rate [67]. Follicular conjunctivitis has been reported as an ophthalmological manifestation of COVID-19. Therefore, eye could be a window for SARS-COV-2 infection and a source for viral transmission [68].

A combination of social distancing, school closure, travel restriction, and quarantine can reduce the attack rate, mortality, and transmission rate [69]. Recent evidence reported that quarantine for people exposed to confirmed or suspected cases of COVID-19 will result in decreasing incidence rate about $44-81 \%$ and lowering mortality rate about $31-63 \%$ [70].

In addition to PPE use and population-based preventive measures, national and international action plan should be implemented on lifestyle intervention such as avoiding mass gathering, promotion of physical activity at home for entire family, group fitness class, adherence to healthy diet and reduction of calorie intake, massive quit smoking consultation, and coaching for stress management are crucial paces for pandemic control.

For effective control of an epidemic, we need evidences on number of mild cases, risk factors for infection, attack rates, 
severity of illness, timing of transmission, and risk factors for severe outcomes and mortality among cases.

Therefore, contact tracing by improving surveillance system can lead to determine asymptomatic and mild diseases. Asymptomatic and mild to moderate cases could be found via household and school surveys by implementing seroepidemiological study and viral shedding assay. Besides, serological testing among individuals who are not suspected to infect with COVID-19 can guide to depict a more accurate feature of the disease severity spectrum.

Viral shedding studies can also detect disease severity, chain of transmission, and duration of patient isolation.

So, school and household surveys could help to find asymptomatic transmission to decide on social distancing, school and university closure, and mass gathering.

COVID-19 occurred in populations with a high burden of uncontrolled chronic diseases. Interaction between SARSCOV-2 and CVD, DM, and obesity caused a high mortality and complication rate in different populations.

CVD and cardiometabolic risks should be controlled. CVD and cerebrovascular disease could be triggered by different infectious disease. Also, increased risk of CVD after an infection is highly possible. Among COVID-19 cases, cardiac damage is eminent.

From scientifically point of view, the COVID-19 pandemic highlighted an urgent need to invest on CVD prevention associated with control of DM, obesity, HTN, cigarette smoking, and high cholesterol level. It reminds us that essential fragility exists in health system infrastructures, which can reveal our vulnerability in the entire global community.

\section{COVID-19 Vaccine}

Vaccine development has a long-term process. So far, ten candidates of vaccine against SARS-COV-2 have been introduced. They are in phase 1 and 2 of clinical trial, and the producers hope that phase 3 will be conducted in summer 2020. These vaccines deliver different viral components into the host cell to trigger immune system response for producing antibody [71]. Moderna and NIAID and BioNTech and Pfizer are working on mRNA vaccine. The University of Oxford and AstraZeneca are working on adenovirus vaccine in phase $2 \mathrm{~B} /$ 3. Inovio Pharmaceuticals is working on DNA vaccine, CanSino Biologics is working on adenovirus vaccine, Sinovac on inactivated virus plus adjuvant, Novavax on protein subunit, and Wuhan Institute of Biological Products and Sinopharm, and Beijing Institute of Biological Products and Sinopharm, Institute of Medical Biology, and Chinese Academy of Medical Sciences are working on inactivated virus in Phase 1/2 [71].

Despite global hunger for SARS-COV-2 vaccine, scientific metrics in vaccine development should be carefully considered because ineffective vaccine products can enhance the disease burden and consequently escalate the pandemic situation.

Finally, it is highly recommended that we should avoid overtreatment during the current pandemic, which means unnecessary antibiotic use can cause unpredictable adverse outcomes.

\section{Discussion}

Tables 1, 2, 3, 4, 5, 6, and 7 have presented the results of metaanalysis of systematically reviewed articles. Seventy-one systematic reviews of COVID-19 included in the review with certainty of evidence were mostly in high- and good-quality score. This is the first systematic review of systematic reviews with meta-analysis focusing on confirmed cases of COVID19 that provide comprehensive evidence available, so far.

The huge burden of adverse outcome following COVID-19 involvement has been exacerbated by comorbidities like hypertension, cardiovascular diseases, diabetes mellitus, cigarette smoking, respiratory diseases, and obesity. COVID-19 is superimposed on uncontrolled pandemic of cardiovascular disease and cardiometabolic risk factors. Now, we are facing to control the current emerging COVID-19 pandemic associated with managing the unfinished business of controlling CVD, DM, HTN, and obesity pandemic.

Results of meta-analysis precisely revealed prognostic factors associated with different outcomes in COVID-19 cases. We categorized the COVID-19 outcomes into three groups including mortality, severity of disease, and disease progression. The most powerful prognostic factors for mortality rate among COVID-19 cases were acute cardiac injury (RR = $10.89)$, previously diagnosed $\mathrm{CVD}(\mathrm{RR}=4.06), \mathrm{DM}(\mathrm{RR}=$ $3.68)$, respiratory disease $(R R=3.51)$, and $H T N(R R=2.86)$ (Table 7).

The most important prognostic factors for disease severity are $C V D(R R=2.83)$ and HTN $(R R=2.20)$. Finally, the most important prognostic factors for disease progression were determined as a combination of fever associated with shortness of breath with $R R=4.16$ and cigarette smoking with $R R=$ 2.19 .

This is the first systematic review with meta-analysis reporting pooled details of different aspect of natural history of COVID-19 based on current published knowledge.

The most prevalent comorbidities associated with SARSCOV-2 infection (Table 4) are HTN 20.7\%, CVD 9.6\%, DM $9.55 \%$, respiratory diseases $7 \%$, and prevalence of cigarette smoking among COVID-19 case reported as 9\%. Therefore, effective long-term control of current pandemic and future threat of global community is crucially depended on controlling of CVD and cardiometabolic risk factors.

One percent of COVID-19 cases have cancer, mostly lung cancers. Mortality rate of these cases was reported as $28.3 \%$ 
with adverse events of $53.6 \%$. It is suggested that risk of discontinuation of cancer treatment is much higher than the risk of COVID-19 [72].

The COVID-19 global pandemic control depends on preventive measures at all four levels. At primary prevention level, PPE, social distancing, quarantine, isolation, effective distancing of $2 \mathrm{~m}$ and more [67-69], and effective vaccine prescription are approaching. Hand hygiene and disinfection of contaminated surfaces are also recommended.

Contact tracing based on precisely designed surveillance systems with serial nucleic acid testing will detect asymptomatic, pre symptomatic, and mild cases of COVID-19. Household, school-based, and workplace survey by using seroepidemiological study and viral shedding assay will accurately depict mode of transmission which can guide determining duration of patient isolation and reopening of schools, universities, and other public places. Current policies have acted based on symptomatic COVID-19 cases, which need to be developed. For enacting more effective preventive measure, it is suggested that decision-makers should broaden current policies to recommendations on asymptomatic and mild cases of COVID-19.

Symptom-based versus test-based approach for ending isolation is mainly dependent upon the resources available. For immunocompromised COVID-19 cases, test-based decision-making for ending isolation is preferred (US CDC guideline). COVID-19 cases that never developed symptoms in isolation can be discontinued 10 days after a positive RT-PCR test. Based on a fact that replicationcompetent virus has not been detected after 10-15 days after symptom onset, discontinuation of isolation for symptomatic patients is recommended after this time, mainly from a practical point of view.

Supplement use of vitamin D; low dose zinc; magnesium; vitamin A, B, E; and selenium has been shown to be efficacious in primary and also secondary prevention of SARSCOV-2 infection [73]. Probiotics might be a useful adjuvant recommendation based on the cross connection between lung and gastrointestinal tract [73].

Hospital care providers recommended using full isolation gun, N95 or higher facemask, eye protection, disposable gloves, and face shields.

So far, in secondary prevention, there is no effective anti-SARS-COV-2-specific viral agent. Available antiviral medication like remdesivir which shortened hospital stay and significantly lowered mortality rate [51] associated with supportive cares for each COVID-19 cases has been used. A systematic review reported the superiority of nucleoside analog with broad-spectrum antiviral activity of Remdesivir associated with interferon beta (IFN- $\beta$ ) to Lopinavir/Ritonavir and IFN- $\beta$ [73]. Remdesivir may enhance protective host immune responses. This study has also reported that favipiravir was more effective than
Lopinavir/Ritonavir [73]. An interventional study did not support the efficacy of lopinavir in COVID-19 cases [74].

Hydroxychloroquine has no significant effect on viral clearance, and there is no evidence about lowering mortality or preventing clinical worsening among COVID-19 cases, besides serious CVD complication reported which questioned the safety of this medication [75].

Steroids have delayed the viral clearance and should be limited to COVID-19 cases with ARDS.

Triage in hospital emergency room could be based on symptoms like fever, cough, shortness of breath, chest pain, headache, body pain, nasal congestion, travel history, and history of contact with confirmed cases of COVID-19 [73].

Interesting laboratory findings in narrative results were mean Hs-CRP level of $52.26 \pm 17.85 \mathrm{~g} / \mathrm{dl}$ in severe cases and mean level of $33.2 \mathrm{~g} / \mathrm{dl}$ in non-severe COVID-19 cases [59].

Mean level of IL6 in severe COVID-19 patients was 56.8 $\mathrm{Pg} / \mathrm{mL}$ and $17.3 \mathrm{Pg} / \mathrm{mL}$ for non-severe cases. Elevated level of IL6 was associated with higher mortality rate of COVID-19 cases [17].

Predictors of severe COVID-19 was presented in a systematic review as age, sex, chest CT findings, CRP level, LD level, and lymphocyte count [76]. Moreover, elevated level of pro-calcitonin will cause about fivefold increased risk of severe COVID-19 (OR = 4.76) [73]. Lymphopenia defined as lymphocyte count below $1100 \mu \mathrm{L}$ demonstrated to be associated with severe COVID-19 presentations (OR = 3.27); it has been figured out that this relationship is stronger in COVID19 cases under 55 years $(\mathrm{OR}=5.32)$ [58].

Liver function tests revealed elevated transaminase, hypoalbuminemia, and prolonged PT time. Histopathological findings of liver in COVID-19 cases demonstrated a pattern compatible with nonspecific inflammation, mild steatosis, congestion, and massive necrosis [40].

So far, child COVID-19 cases were reported as $1-5 \%$ of the total COVID-19 cases [31]. This unexpected low rate of SARS-COV-2 infection among the younger population has been described in a systematic review as lower medical attention to the infection among children [32].

Narrative synthesis revealed the common neurological symptoms of COVID-19 in one systematic review including hyposmia, headache, weakness, and altered consciousness. Furthermore, COVID-19 has been associated with encephalitis, demyelination, neuropathy, and stroke [38].

Obesity $\left(\mathrm{BMI}>35 \mathrm{~kg} / \mathrm{m}^{2}\right)$ has been associated with increased risk of mechanical ventilation in COVID-19 patients with an $\mathrm{OR}=7.36$, and also higher mortality rate [64].

A systematic review reported that enacting quarantine for people exposed to or suspected with SARS-COV-2 infection will decrease the incidence rate about $44-81 \%$ and lowering mortality rate about $31-63 \%$ [70]. 


\section{Conclusion}

Progressing global pandemic of COVID-19 is a systemic inflammation with multiple-organ involvement including blood vessels, lung, heart, central nervous system, liver, gastrointestinal system, kidney, eyes, and other organs. SARS-COV-2 infection involves adult and children, infant, neonates, pregnant women, and elderly people. Recent reports describing complement-mediated thrombotic microangiopathy-like syndrome in COVID-19 cases have complicated the pathophysiological feature of the disease. Rapidly spreading COVID-19, which is categorized as a highly infectious contagious disease, transmits via both air born and droplet.

The most prevalent comorbidities associated with SARSCOV-2 infection are HTN 20.7\%, CVD 9.6\%, DM 9.55\%, respiratory diseases $7 \%$, and prevalence of cigarette smoking among COVID-19 case reported as $9 \%$.

The COVID-19 outcomes are categorized into three groups including, mortality, severity of disease, and disease progression. The most powerful prognostic factors for mortality rate among COVID-19 cases were acute cardiac injury, previously diagnosed CVD, DM, respiratory disease, and HTN. The most important prognostic factors for disease severity are CVD and HTN. Finally, the most important prognostic factor for disease progression determined is a combination of fever associated with shortness of breath and cigarette smoking.

All age groups are at risk for the disease with a higher susceptibility for patients with associated comorbidity. High case fatality rate is another aspect of the current pandemic. The coincidence of the COVID-19 pandemic and CVD and cardiometabolic risk pandemic exacerbated the adverse outcomes of SARS-COV-2 infection.

Authors' Contributions Dr. Zinat Nadia Hatmi has designed, conducted, and statistically analyzed the data and prepared the manuscript.

Data Availability They are available.

\section{Compliance with Ethical Standards}

Conflict of Interest The author declare that she has no conflict of interest.

Ethical Approval Not applicable.

Consent of Participate Not applicable.

Consent for Publication Neither the manuscript nor any parts of its content are currently under consideration or published in other journals.

Code Availability Statistical package of IBM SPSS Statistics for Windows, Version 22.0. Armonk, NY: IBM Corp has been used.

\section{References}

1. Fried JA, Ramasubbu K, Bhatt R, Topkara VK, Clerkin KJ, Horn E, et al. The variety of cardiovascular presentations of COVID-19. Circulation. 2020;141:1930-6.

2. Akhmerov A, Marban E. COVID-19 and the heart. Circ Res. 2020;126(10):1443-55.

3. Pellicori P. At the heart of COVID-19. Eur Heart J. 2020;41(19): 1830-2.

4. Guyatt G, Oxman AD, Akl EA, Kunz R, Vist G, Brozek J, et al. GRADE guidelines: 1. Introduction-GRADE evidence profiles and summary of findings tables. J Clin Epidemiol. 2011;64(4):383-94.

5. Foroutan F, Guyatt G, Zuk V, Vandvik PO, Alba AC, Mustafa R, et al. GRADE guidelines 28: use of GRADE for the assessment of evidence about prognostic factors: rating certainty in identification of groups of patients with different absolute risks. J Clin Epidemiol. 2020;121:62-70.

6. Guyatt GH, Ebrahim S, Alonso-Coello P, Johnston BC, Mathioudakis AG, Briel M, et al. GRADE guidelines 17: assessing the risk of bias associated with missing participant outcome data in a body of evidence. J Clin Epidemiol. 2017;87:14-22.

7. Guyatt GH, Oxman AD, Kunz R, Brozek J, Alonso-Coello P, Rind $\mathrm{D}$, et al. GRADE guidelines 6 . Rating the quality of evidenceimprecision. J Clin Epidemiol. 2011;64(12):1283-93.

8. Guyatt GH, Oxman AD, Kunz R, Woodcock J, Brozek J, Helfand $M$, et al. GRADE guidelines: 8 . Rating the quality of evidenceindirectness. J Clin Epidemiol. 2011;64(12):1303-10.

9. Guyatt GH, Oxman AD, Kunz R, Woodcock J, Brozek J, Helfand $\mathrm{M}$, et al. GRADE guidelines: 7. Rating the quality of evidenceinconsistency. J Clin Epidemiol. 2011;64(12):1294-302.

10. Guyatt GH, Oxman AD, Montori V, Vist G, Kunz R, Brozek J, et al. GRADE guidelines: 5 . Rating the quality of evidencepublication bias. J Clin Epidemiol. 2011;64(12):1277-82.

11. Guyatt GH, Oxman AD, Sultan S, Glasziou P, Akl EA, AlonsoCoello P, et al. GRADE guidelines: 9. Rating up the quality of evidence. J Clin Epidemiol. 2011;64(12):1311-6.

12. Guyatt GH, Oxman AD, Vist G, Kunz R, Brozek J, Alonso-Coello P, et al. GRADE guidelines: 4. Rating the quality of evidence-study limitations (risk of bias). J Clin Epidemiol. 2011;64(4):407-15.

13. Guyatt GH, Thorlund K, Oxman AD, Walter SD, Patrick D, Furukawa TA, et al. GRADE guidelines: 13. Preparing summary of findings tables and evidence profiles-continuous outcomes. J Clin Epidemiol. 2013;66(2):173-83.

14. Lovato A, de Filippis C. Clinical presentation of COVID-19: a systematic review focusing on upper airway symptoms. Ear Nose Throat J. 2020;145561320920762.

15. Luers JC, Rokohl AC, Loreck N, Wawer Matos PA, Augustin M, Dewald F, et al. Olfactory and gustatory dysfunction in coronavirus disease 19 (COVID-19). Clin Infect Dis. 2020;71:2262-4.

16. Siordia JA Jr. Epidemiology and clinical features of COVID-19: a review of current literature. J Clin Virol. 2020;127:104357.

17. Aziz M, Perisetti A, Lee-Smith WM, Gajendran M, Bansal P, Goyal H. Taste changes (Dysgeusia) in COVID-19: a systematic review and metaanalysis. Gastroenterology. 2020;159:1132-3.

18. Sugimoto T, Mizuno A, Kishi T, Ito N, Matsumoto C, Fukuda M, et al. Coronavirus disease 2019 (COVID-19) information for cardiologists- systematic literature review and additional analysis. Circ J. 2020;84:1039-43.

19. Santoso A, Pranata R, Wibowo A, Al-Farabi MJ, Huang I, Antariksa B. Cardiac injury is associated with mortality and critically ill pneumonia in COVID-19: a meta-analysis. Am J Emerg Med. 2020.

20. Li JW, Han TW, Woodward M, Anderson CS, Zhou H, Chen YD, et al. The impact of 2019 novel coronavirus on heart injury: a 
systematic review and Meta-analysis. Prog Cardiovasc Dis. 2020;63:518-24.

21. Kunutsor SK, Laukkanen JA. Cardiovascular complications in COVID-19: a systematic review and meta-analysis. J Inf Secur. 2020.

22. Li X, Guan B, Su T, Liu W, Chen M, Bin Waleed K, et al. Impact of cardiovascular disease and cardiac injury on in-hospital mortality in patients with COVID-19: a systematic review and meta-analysis. Heart. 2020;106:1142-7.

23. Cheung KS, Hung IF, Chan PP, Lung KC, Tso E, Liu R, et al. Gastrointestinal manifestations of SARS-CoV-2 infection and virus load in fecal samples from the Hong Kong cohort and systematic review and meta-analysis. Gastroenterology. 2020.

24. Mao R, Qiu Y, He JS, Tan JY, Li XH, Liang J, et al. Manifestations and prognosis of gastrointestinal and liver involvement in patients with COVID-19: a systematic review and meta-analysis. Lancet Gastroenterol Hepatol. 2020;5:667-78.

25. Suresh Kumar VC, Mukherjee S, Harne PS, Subedi A, Ganapathy MK, Patthipati VS, et al. Novelty in the gut: a systematic review and meta-analysis of the gastrointestinal manifestations of COVID19. BMJ Open Gastroenterol. 2020;7(1).

26. Chang TH, Wu JL, Chang LY. Clinical characteristics and diagnostic challenges of pediatric COVID-19: a systematic review and meta-analysis. J Formos Med Assoc. 2020;119(5):982-9.

27. Di Mascio D, Khalil A, Saccone G, Rizzo G, Buca D, Liberati M, et al. Outcome of coronavirus spectrum infections (SARS, MERS, COVID 1-19) during pregnancy: a systematic review and metaanalysis. Am J Obstet Gynecol MFM 2020:100107.

28. Duran P, Berman S, Niermeyer S, Jaenisch T, Forster T. Gomez Ponce de Leon R, et al. COVID-19 and newborn health: systematic review. Rev Panam Salud Publica. 2020;44:e54.

29. Doria M, Peixinho C, Laranjo M, Varejao AM, Silva PT. Covid-19 during pregnancy: a case series from an universally tested population from the north of Portugal. Eur J Obstet Gynecol Reprod Biol. 2020;250:261-2.

30. Smith V, Seo D, Warty R, Payne O, Salih M, Chin KL, et al. Maternal and neonatal outcomes associated with COVID-19 infection: a systematic review. PLoS One. 2020;15(6):e0234187.

31. Ludvigsson JF. Systematic review of COVID-19 in children shows milder cases and a better prognosis than adults. Acta Paediatr. 2020;109(6):1088-95.

32. Mehta NS, Mytton OT, Mullins EWS, Fowler TA, Falconer CL, Murphy OB, et al. SARS-CoV-2 (COVID-19): what do we know about children? A systematic review. Clin Infect Dis. 2020.

33. Chan VW, Chiu PK, Yee CH, Yuan Y, Ng CF, Teoh JY. A systematic review on COVID-19: urological manifestations, viral RNA detection and special considerations in urological conditions. World J Urol. 2020.

34. Yang J, Zheng Y, Gou X, Pu K, Chen Z, Guo Q, et al. Prevalence of comorbidities and its effects in patients infected with SARS-CoV-2: a systematic review and meta-analysis. Int J Infect Dis. 2020;94: 91-5.

35. Liu H, Chen S, Liu M, Nie H, Lu H. Comorbid chronic diseases are strongly correlated with disease severity among COVID-19 patients: a systematic review and meta-analysis. Aging Dis. 2020;11(3):668-78.

36. Helms J, Kremer S, Merdji H, Clere-Jehl R, Schenck M, Kummerlen C, et al. Neurologic features in severe SARS-CoV-2 infection. N Engl J Med. 2020;382:2268-70.

37. Helms J, Kremer S, Meziani F. More on neurologic features in severe SARS-CoV-2 infection. Reply. N Engl J Med. 2020;382.

38. Montalvan V, Lee J, Bueso T, De Toledo J, Rivas K. Neurological manifestations of COVID-19 and other coronavirus infections: a systematic review. Clin Neurol Neurosurg. 2020;194:105921.

39. Rogers JP, Chesney E, Oliver D, Pollak TA, McGuire P, Fusar-Poli $\mathrm{P}$, et al. Psychiatric and neuropsychiatric presentations associated with severe coronavirus infections: a systematic review and metaanalysis with comparison to the COVID-19 pandemic. Lancet Psychiatry. 2020;7:611-27.

40. Kukla M, Skonieczna-Zydecka K, Kotfis K, Maciejewska D, Loniewski I, Lara LF, et al. COVID-19, MERS and SARS with concomitant liver injury-systematic review of the existing literature. J Clin Med. 2020;9(5).

41. Ho D, Low R, Tong L, Gupta V, Veeraraghavan A, Agrawal R. COVID-19 and the ocular surface: a review of transmission and manifestations. Ocul Immunol Inflamm. 2020:1-9.

42. Berlin I, Thomas D, Le Faou AL, Cornuz J. COVID-19 and smoking. Nicotine Tob Res. 2020;22:1650-2.

43. Alqahtani JS, Oyelade T, Aldhahir AM, Alghamdi SM, Almehmadi M, Alqahtani AS, et al. Prevalence, severity and mortality associated with COPD and smoking in patients with COVID19: a rapid systematic review and meta-analysis. PLoS One. 2020;15(5): $\mathrm{e} 0233147$.

44. Tang YW, Schmitz JE, Persing DH, Stratton CW. Laboratory siagnosis of COVID-19: current issues and challenges. J Clin Microbiol. 2020;58(6).

45. Setti L, Passarini F, De Gennaro G, Barbieri P, Perrone MG, Borelli $\mathrm{M}$, et al. Airborne transmission route of COVID-19: why 2 meters/6 feet of inter-personal distance could not be enough. Int J Environ Res Public Health. 2020;17(8).

46. Bourouiba L. Turbulent gas clouds and respiratory pathogen emissions: potential implications for reducing transmission of COVID19. JAMA. 2020

47. Ojha V, Mani A, Pandey NN, Sharma S, Kumar S. CT in coronavirus disease 2019 (COVID-19): a systematic review of chest CT findings in 4410 adult patients. Eur Radiol. 2020;30:6129-38.

48. Sun Z, Zhang N, Li Y, Xu X. A systematic review of chest imaging findings in COVID-19. Quant Imaging Med Surg. 2020;10(5): 1058-79.

49. Lansbury L, Lim B, Baskaran V, Lim WS. Co-infections in people with COVID-19: a systematic review and meta-analysis. J Inf Secur. 2020.

50. Beigel JH, Tomashek KM, Dodd LE, Mehta AK, Zingman BS, Kalil AC, et al. Remdesivir for the treatment of Covid-19 - preliminary report. N Engl J Med. 2020;383:1813-26.

51. Gebrie D, Getnet D, Manyazewal T. Efficacy of remdesivir in patients with COVID-19: a protocol for systematic review and metaanalysis of randomised controlled trials. BMJ Open. 2020;10(6): e039159.

52. Fajgenbaum DC, Khor JS, Gorzewski A, Tamakloe MA, Powers $\mathrm{V}$, Kakkis JJ, et al. Treatments administered to the first 9152 reported cases of COVID-19: a systematic review. Infect Dis Ther. 2020;9:435-49.

53. Zhong H, Wang Y, Zhang ZL, Liu YX, Le KJ, Cui M, et al. Efficacy and safety of current therapeutic options for COVID-19 lessons to be learnt from SARS and MERS epidemic: a systematic review and meta-analysis. Pharmacol Res. 2020;157:104872.

54. Chowdhury MS, Rathod J, Gernsheimer J. A rapid systematic review of clinical trials utilizing chloroquine and Hydroxychloroquine as a treatment for COVID-19. Acad Emerg Med. 2020.

55. Das $\mathrm{S}$, Bhowmick S, Tiwari S, Sen S. An updated systematic review of the therapeutic role of hydroxychloroquine in coronavirus disease-19 (COVID-19). Clin Drug Investig. 2020;40:591-601.

56. Jankelson L, Karam G, Becker ML, Chinitz LA, Tsai MC. QT prolongation, torsades de pointes, and sudden death with short courses of chloroquine or hydroxychloroquine as used in COVID19: a systematic review. Heart Rhythm. 2020;17:1472-9.

57. Devasenapathy N, Ye Z, Loeb M, Fang F, Najafabadi BT, Xiao Y, et al. Efficacy and safety of convalescent plasma for severe COVID-19 based on evidence in other severe respiratory viral 
infections: a systematic review and meta-analysis. CMAJ. 2020;192:E745-55.

58. Huang I, Pranata R. Lymphopenia in severe coronavirus disease2019 (COVID-19): systematic review and meta-analysis. J Intensive Care. 2020;8:36.

59. Kermali M, Khalsa RK, Pillai K, Ismail Z, Harky A. The role of biomarkers in diagnosis of COVID-19 - a systematic review. Life Sci. 2020;254:117788.

60. Jain V, Yuan JM. Predictive symptoms and comorbidities for severe COVID-19 and intensive care unit admission: a systematic review and meta-analysis. Int J Public Health. 2020;65:533-46.

61. Pranata R, Huang I, Lim MA, Wahjoepramono PEJ, July J. Impact of cerebrovascular and cardiovascular diseases on mortality and severity of COVID-19 - systematic review, meta-analysis, and meta-regression. J Stroke Cerebrovasc Dis. 2020;104949.

62. Pranata R, Huang I, Lukito AA, Raharjo SB. Elevated N-terminal pro-brain natriuretic peptide is associated with increased mortality in patients with COVID-19: systematic review and meta-analysis. Postgrad Med J. 2020;96:387-91.

63. Pranata R, Lim MA, Huang I, Raharjo SB, Lukito AA. Hypertension is associated with increased mortality and severity of disease in COVID-19 pneumonia: a systematic review, metaanalysis and meta-regression. J Renin-Angiotensin-Aldosterone Syst. 2020;21(2):1470320320926899.

64. Tamara A, Tahapary DL. Obesity as a predictor for a poor prognosis of COVID-19: a systematic review. Diabetes Metab Syndr. 2020;14(4):655-9.

65. Keeley P, Buchanan D, Carolan C, Pivodic L, Tavabie S, Noble S. Symptom burden and clinical profile of COVID-19 deaths: a rapid systematic review and evidence summary. BMJ Support Palliat Care. 2020;10:381-4.

66. Pujadas E, Chaudhry F, McBride R, Richter F, Zhao S, Wajnberg A, et al. SARS-CoV-2 viral load predicts COVID-19 mortality. Lancet Respir Med. 2020;8:e70.

67. Chu DK, Akl EA, Duda S, Solo K, Yaacoub S, Schunemann HJ, et al. Physical distancing, face masks, and eye protection to prevent person-to-person transmission of SARS-CoV-2 and COVID-19: a systematic review and meta-analysis. Lancet. 2020;395:1973-87.
68. Dockery DM, Rowe SG, Murphy MA, Krzystolik MG. The ocular manifestations and transmission of COVID-19: recommendations for prevention. J Emerg Med. 2020.

69. Nussbaumer-Streit B, Mayr V, Dobrescu AI, Chapman A, Persad E, Klerings I, et al. Quarantine alone or in combination with other public health measures to control COVID-19: a rapid review. Cochrane Database Syst Rev. 2020;4:CD013574.

70. Flumignan RLG, Nakano LCU, Pascoal PIF, Santos BCD, Correia RM, Silveira BP, et al. Evidence from Cochrane systematic reviews for controlling the dissemination of COVID-19 infection. A narrative review. Sao Paulo Med J. 2020.

71. Mullard A. COVID-19 vaccine development pipeline gears up. Lancet. 2020;395(10239):1751-2.

72. Moujaess E, Kourie HR, Ghosn M. Cancer patients and research during COVID-19 pandemic: a systematic review of current evidence. Crit Rev Oncol Hematol. 2020;150:102972.

73. Balla M, Merugu GP, Patel M, Koduri NM, Gayam V, Adapa S, et al. COVID-19, modern pandemic: a systematic review from front-line health care providers' perspective. J Clin Med Res. 2020;12(4):215-29.

74. Ford N, Vitoria M, Rangaraj A, Norris SL, Calmy A, Doherty M. Systematic review of the efficacy and safety of antiretroviral drugs against SARS, MERS or COVID-19: initial assessment. J Int AIDS Soc. 2020;23(4):e25489.

75. Sarma P, Kaur H, Kumar H, Mahendru D, Avti P, Bhattacharyya A, et al. Virological and clinical cure in Covid-19 patients treated with hydroxychloroquine: a systematic review and meta-analysis. J Med Virol. 2020;92:776-85.

76. Wynants L, Van Calster B, Bonten MMJ, Collins GS, Debray TPA, De Vos M, et al. Prediction models for diagnosis and prognosis of covid-19 infection: systematic review and critical appraisal. BMJ. 2020;369:m1328.

Publisher's Note Springer Nature remains neutral with regard to jurisdictional claims in published maps and institutional affiliations. 